\title{
Study Of Measurements Leakage Current In Oil Transformer
}

\author{
Hassan J. Mohammed. \\ Department of Materials Eng. , College of Engineering , University of Diyala \\ Hassanjasim08@gmail.com
}

\begin{abstract}
The oil transformer is used in (H.V ) ment's to avoid the electrical breakdown, and heat effect, so that the oil using as an insulation and cooling in electrical instruments to prevent the failure in the transformer. In our research the measurements of the breakdown voltage as a function of electrodes distance, and leakage current for the oil transformer had been done, also the effect of temperature at the breakdown voltage was studied.
\end{abstract}

Keyword :Oil Transformer, Electric Discharge ,Leakage current.

Paper History:(Received :14-12-2017 ; Accepted: 6-32018)

\section{Introduction}

Certain types of electrical faults cause the breakdown of oil in service to comparatively volatile low molecular weight hydrocarbons or to inflammable gases which, having dissolving in the transformer oil, result in a reduction of the closed flash point of the oil service. It is therefore important to have on record the initial flash point of the oil at the commissioning of the transformer ,so that comparatively small changes occurring during service can be detected 1,2$]$.

Since the operating temperature of the oil in service is very much lower than the allowable flash point of transformer oil, minor differences in flash point have no very great important. On the other hand a change in the closed flash point may indicate the contamination of the oil by more volatile products which, even though present only small quantities, may constitute an explosion hazard when the oil is heated in ordinary service, due to a high concentration of inflammable vapour above the oil surface Such contamination has been known to occur upon removing oil from a transformer for inspection

The present experimental setup was capable of producing bubble pre-breakdown and breakdown voltage in four variation temperatures $\left(27,35,43,57^{\circ} \mathrm{C}\right)$ by $\mathrm{DC}$ positive applied voltage $(0$ -

$70 \mathrm{kV}),(20 \mathrm{mAmp})$, over the range of gap length from (2 to $5 \mathrm{~cm}$ ), under humidity and Lab. ambient, We observer practically that in non-uniformity fields in oil transformer, pre-breakdown or initial voltage less than or smaller than the breakdown

purposes, when using drums which had previously contained a volatile solvent.

The closed flash point of oil is measured by means of the Pensky- Marttens apparatus. It is a guide to the temperature of the oil at which the combustible vapour in a confined air space above it accumulates sufficiently to 'flash' upon the application of a flame or other equivalent source of ignition, such as an arc or a spark[1,2,3].It will be recognized that fire and explosion are to some degree potential risks whenever petroleum oils are component parts of electrical equipment.

The effectiveness of transformer cooling will be maintained only if the oil has a good oxidation stability so that the viscosity is substantially unchanged during the many years of service life expected, and no solid materials, know by the general name 'sludge', are formed. Sludge formation reduces the efficacy of cooling in several ways. Deposition of sludge upon the insulation seriously impedes the condition of heat from the conductors and other parts from the conductors and other from which the removal of heat is essential. Sludge deposition may also occur in the oil ducts of windings, so that the rate of oil circulation over the heating surfaces is reduced Further, sludge may accumulate in those parts of the unit employed for cooling the oil, this is not only equivalent to lagging the cooling surfaces, but also results in a loss of efficiency due to an reduction of the oil circulation rate within the transformer unit as a whole. The cumulative effect of sludging, therefore, is an increases of operating temperature within the transformer , the serious implications of which are only too well known. [4,5]

In experimental studies mineral oil are normally used at high voltage strength, in the applications like (H.V) bushing, the oil dielectric is used as impregnates in (H.V) cables electrolyte resistors capacitor, and filling tank of transformer ,also can be used in circuit breakers, the oil also act as heat transfer against in transformer, so that the oil used as high electrical insulation[6,7]. 
By choosing the most significant experimental results from extensive literature, it is hoped to present an overall background and research achievement of breakdown mechanisms in transformer liquids over the past 100 years. It should be kept in mind that most of the previous investigations made use of mineral oil or saturated hydrocarbon liquids. With the successful usage of esters in distribution transformers in recent years, much research effort was devoted to preparing for the application of esters in power apparatus at higher voltage ratings. It is therefore of great importance to understand the dielectric characteristics of esters, especially at large oil gaps and high voltage ratings[8,9].. Nevertheless, a thorough review of breakdown mechanisms in mineral oil is still of great necessity, to provide both the experimental methods and the inspiring thoughts to the study of breakdown mechanisms in esters.

The breakdown of insulating liquids is not simple to explain and the mechanism responsible for the initiation of breakdown is still open to controversy. Many breakdown theories have been put forward since the start of research on this subject, which can be generally divided into three categories. 1 Ionization theory believes that electrons can be accelerated to ionization energy at high voltage, and the accumulative ionization-collision process will lead to the final breakdown[6]. There are two ionization mechanism:( Weakest-link theory, and Streamer theory) $[9,10,11]$.

\section{Experimental detail}

Inspection of oil should be made at least annually throughout the life the transformer, and there are circumstances in the which more frequent examination is advisable .Figure(1)

illustrate standard oil test cell. The pool made of glass or transparent plastic materials, with effective volumes of
$15 \mathrm{~L}$,preferably fitted with suitable oil. The electrodes made of brass or stainless steel, are either spherical and of 18 to $20 \mathrm{~mm}$ diameter as shown in figure.

So that many experiments have been achieved to examination the oil transformer pre-breakdown, the prebreakdown details such as the determination of electric breakdown ,electron energy distribution, and divergence of field [12-15].

The electric strength test in the specification, although included here because it is directly associated with the use of oil as an insulant, is nevertheless not a test for the measurement of electrical quality in the normal sense, but mainly provides an indication of the physical condition of the oil. This emphasis is brought out in the specification itself, where it is stated that the electric strength is very greatly affected by the most minute traces of certain impurities.

It is choose the oil transformer as insulation, we will carried out many investigated by the applied electric high field strength (voltage alternating)on the oil with hemisphere electrodes. Each investigate return three times on the gap length from $(2-5 \mathrm{~mm})$, under thermal hater with difference temperatures, after end of

breakdown the electrodes are cleaner and polishing. The measurements of leakage current taken from prebreakdown voltage, until the breakdown occur, the oil supply the dielectric required (insulation ) and also made as a cools of coil and tanks walls of transformer, therefore most in the oil state over the enough operating for the range of $\left(\mathrm{T}^{\mathrm{o}}\right)$ between $\left(27{ }^{\circ} \mathrm{C}\right.$ and $\left.57{ }^{\circ} \mathrm{C}\right)$, therefore, it is limits of $\left(\mathrm{T}^{\circ}\right)$ for the dielectric where the insulation depends on the raise of temperature. The electric circuit consists of resistor more than $10 \mathrm{M} \Omega$ to protection of the H.V. power



Figure (1): The schematic diagram of Oil test cell 
supply, the two resistors to limits of the current $50 \mathrm{M} \Omega$, and voltage divider The variation of electric pre- to read of the applied voltage on the electrodes. The measurement procedure in the ambient of the Lab for humidity .

Experimental was achieved by using (H .V DC supply more than $71 \mathrm{kV}, 19.9 \mathrm{~mA}$ ), give (+ve or -ve polarity. The H.V terminals of the difference examination pass through a $\mathrm{R} \approx 8 \mathrm{M} \Omega$ oil-impregnated, also the current



To determine the pre-breakdown or breakdown voltage, potential increases until the breakdown occur. The wave shape and measure its parameters, beside the pulse on oscilloscope its observer , and measuring used. The initial values and breakdown voltage was measuring from instruments of H.V measurements that called (voltage divider) seen in Figs.(1). The system not valid at our lab. ,this system is employed with regard to the current it and measured in-directly by investigate the voltage a through a resistor (49 $\Omega$ ) connected to the earth. All the examinations were achieved "Diyala Electricity Distribution Directorate"

\section{Results And Discussion}

The variation of electric pre-breakdown potential with gap length for oil transformer at temperature $(27,35,43$, and $57^{\circ} \mathrm{C}$ ) are drawn in figures (2-5)
It is observed from these figures that breakdown voltage is directionally proportional with the gap spacing, and this is true because the breakdown voltage for any material is effected by the electric field which is equal to the negative voltage gradient.

The electrical potential increases slightly with change voltage, then the breakdown occur. The voltage difference supply is reached to point that represent the discharge voltage, initial the spark or bubble appears between the hemisphere electrodes. On the oil test pool the investigations is achieved

three times. To obtains the results. The sphere electrodes are mounted on the $\mathrm{x}$-axis (horizontal place ) as a gap length from $(2-5 \mathrm{~mm})$

Figures (2)-( 5), shows the relation -ship between breakdown voltage and space gap ,that investigated in oil transformer with temperature .Its changed from (27to $57)^{\circ} \mathrm{C}$, these measurements from figures indicated breakdown strength raise with large the distance ,for the same temperature .while the breakdown strength lower with increase the thermal for difference degree of temperatures. From figures we shows that the breakdown voltage start toward the stability, because of the ionization and streamer theory that oil reaches to saturation state.

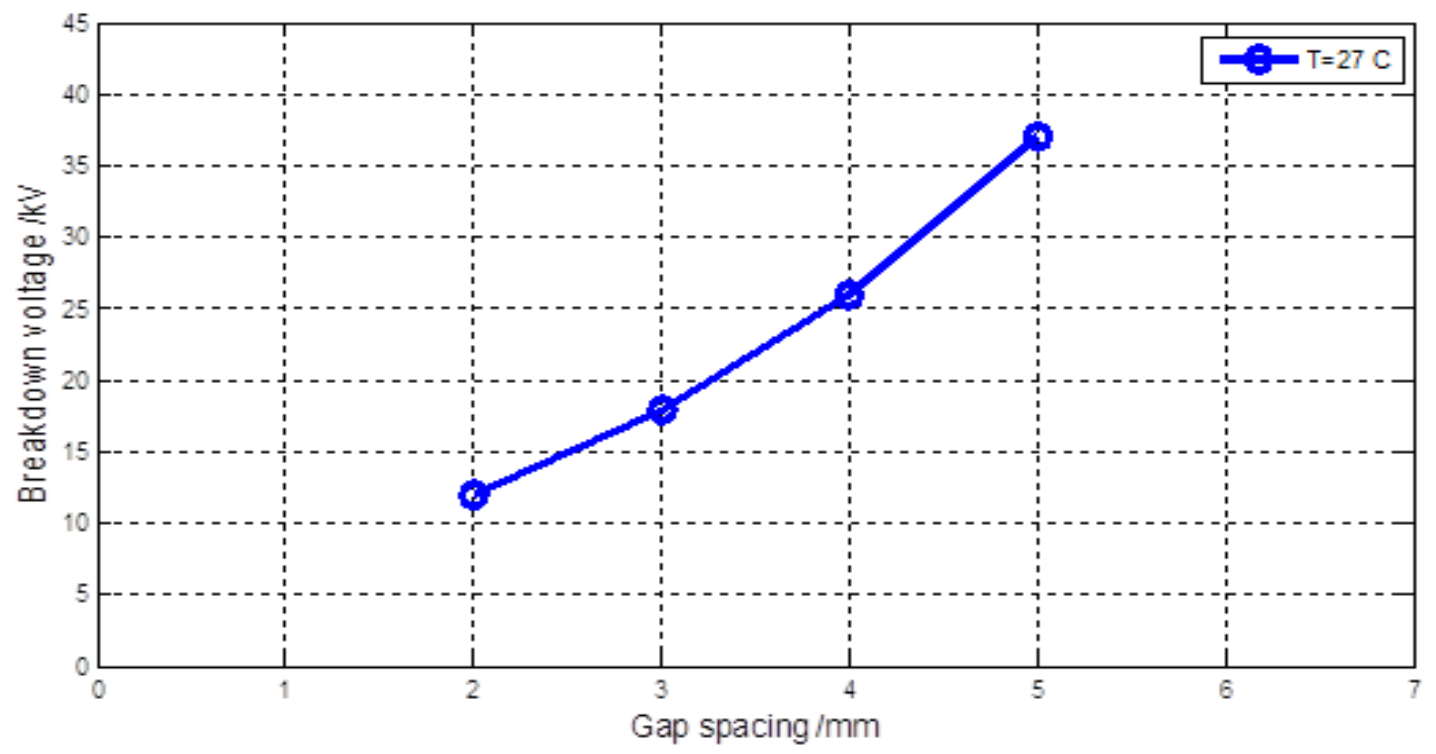

Fig.(2):Illustrate breakdown of oil transformer as gap length with temperature $\left(27^{\circ} \mathrm{C}\right)$. 


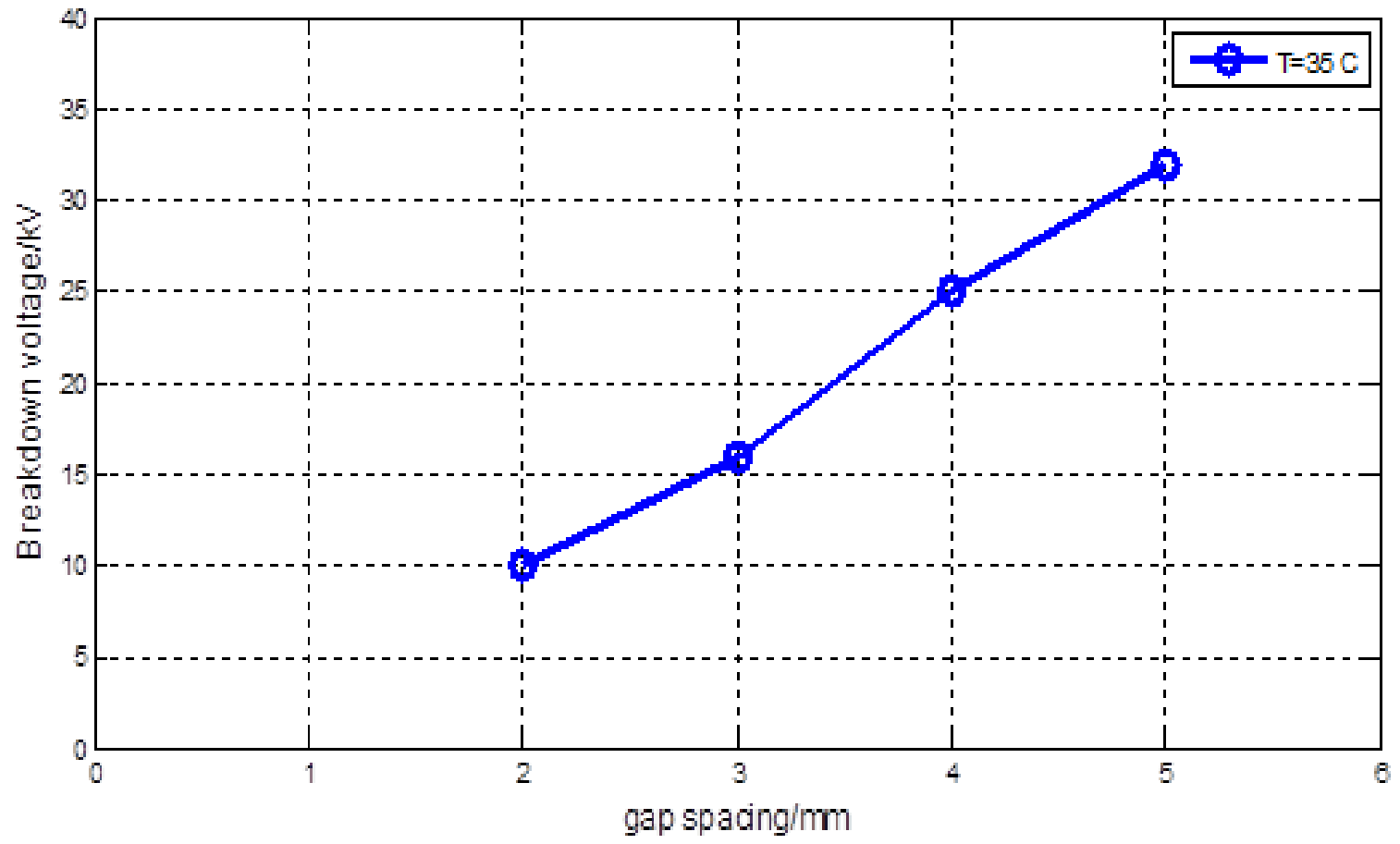

Fig.(3):Illustrate breakdown of oil transformer as gap length for oil transformer with temperature $\left(35^{\circ} \mathrm{C}\right)$

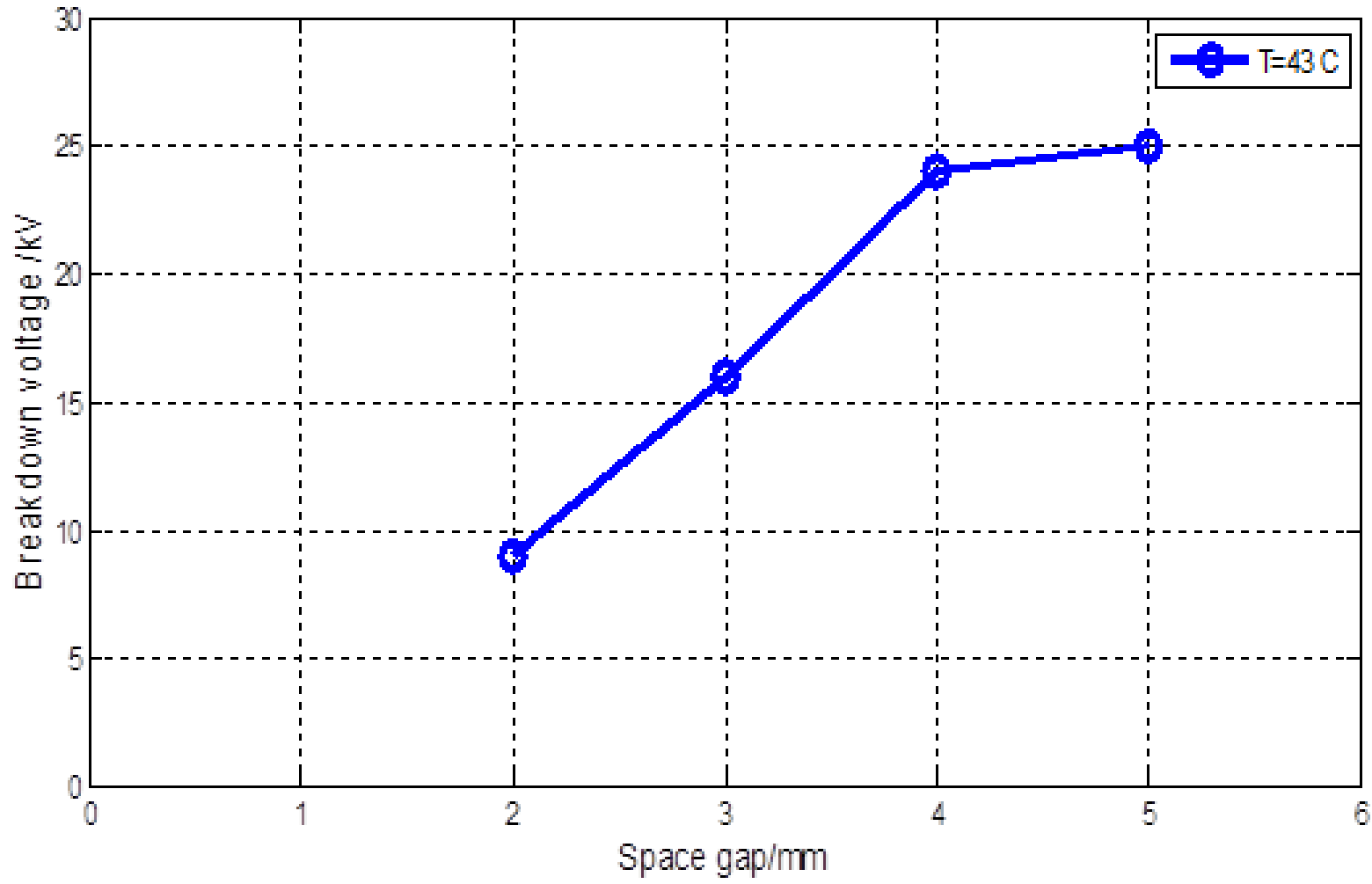

Fig.(4):Illustrate breakdown of oil transformer as gap length with temperature $\left(43^{\circ} \mathrm{C}\right)$. 


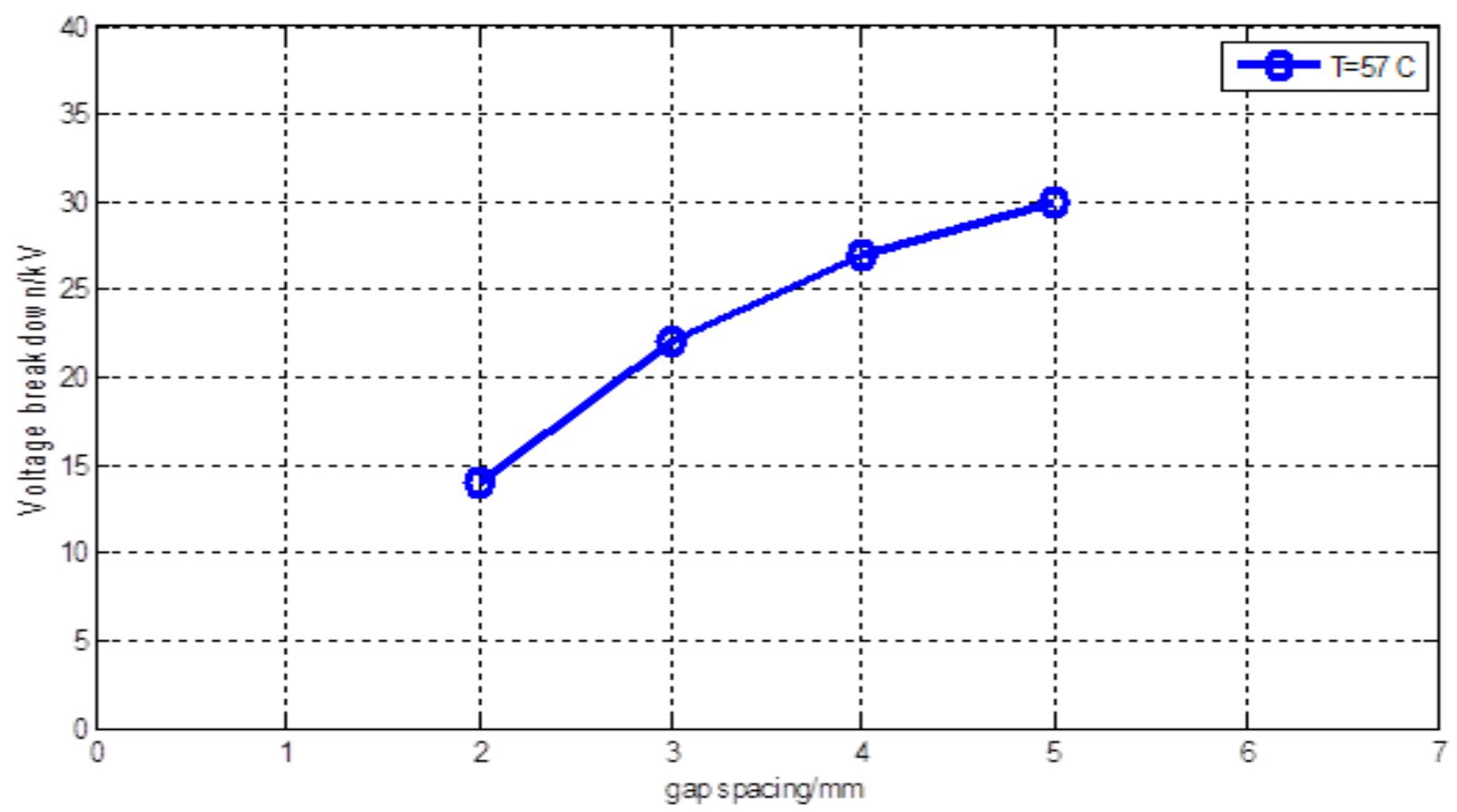

Fig.(5):Illustrate electrical breakdown versus gap distance of oil transformer with temperature $\left(57^{\circ} \mathrm{C}\right)$.

Figure (6), Shows that electrical breakdown in oil transformer as difference temperatures that variation from $\left(27\right.$ to $\left.57^{\circ} \mathrm{C}\right)$, to investigated of oil transformer with fix the constant of distance $(2,5) \mathrm{mm}$.

The measurements shows the breakdown voltage decrease with increases the temperatures , and it appeared on the curve minimum value as shown in figures

The effect of temperature at the breakdown was investigated, and the results of our study is represented by

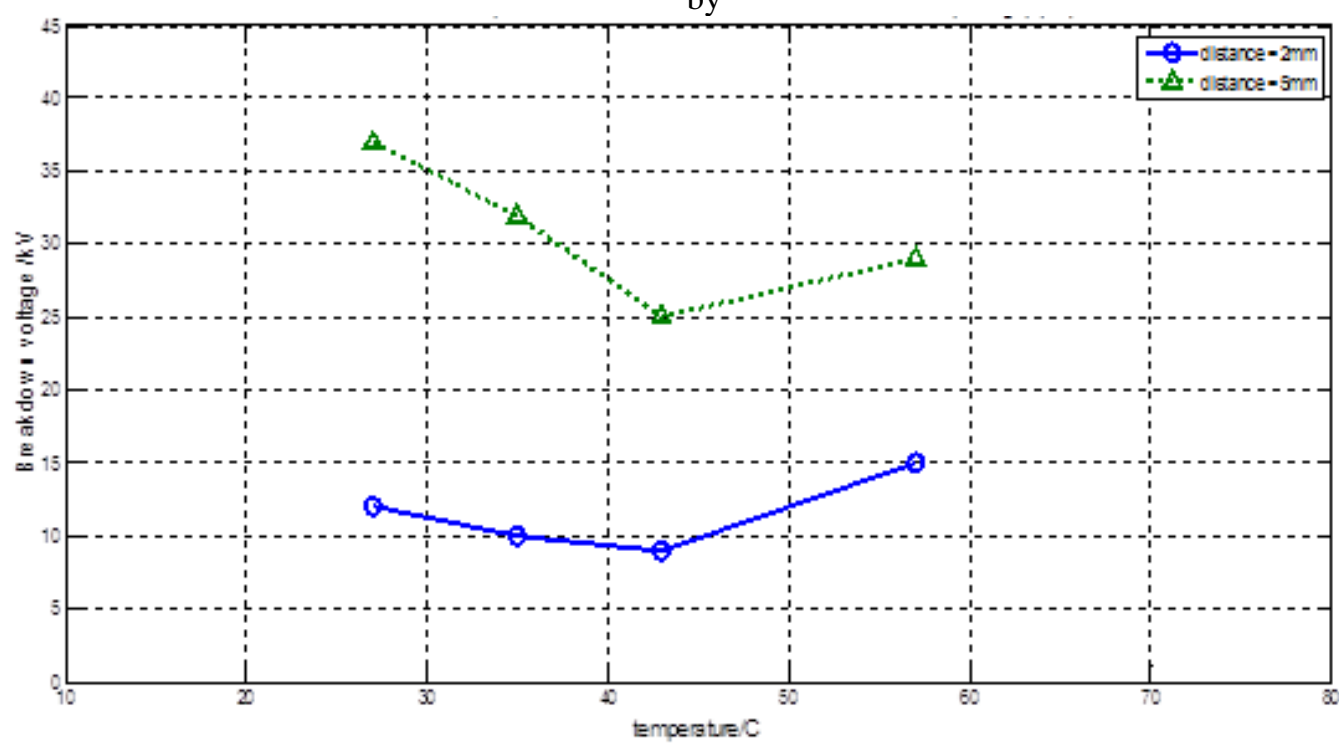

Fig. (6):Illustrate breakdown voltage discharge as temperatures for oil transformer with distance $=(2,5) \mathrm{mm}$.

Figures (7),Indicate the breakdown voltage and difference gap geometry to investigated of oil transformer with fix the temperature $\left(27,43^{\circ} \mathrm{C}\right)$.

Figure (6), which explain that the breakdown voltage is decreased with increasing temperature until the temperature reads $43{ }^{\circ} \mathrm{C}$, then it is raised with increasing temperature. The form of the relation between the breakdown voltage and temperature are parabola. A critical value of (minimum curve ), with which a minimum breakdown voltage was associated was found to be $\left(43^{\circ} \mathrm{C}\right)$ for a gap length $(2 \mathrm{~cm}$, and $5 \mathrm{~cm})$.This might be due to the various physical processes accompanying the breakdown mechanism.

The measurement illustrate the breakdown voltage increase with increases temperatures. 


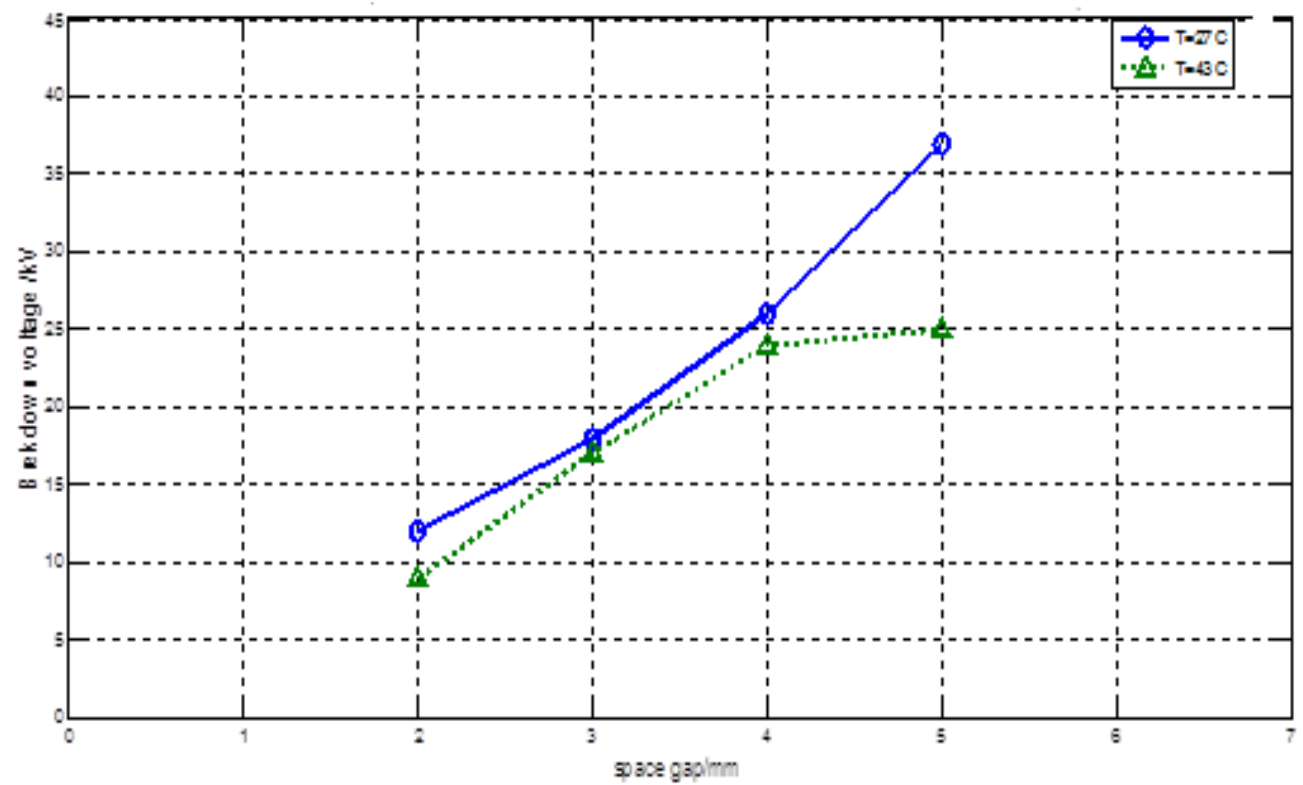

Fig.(7):Indicate the breakdown as gap length for oil transformer with temperature $\left(27,43^{\circ} \mathrm{C}\right)$.

Figures (8)to (10), Indicate the relationship between leakage current and with variation of pre-breakdown voltage in oil transformer with difference temperature $\left(27,43^{\circ}, 57 \mathrm{C}\right)$, and gap spacing. if we applied a small voltage to the electrodes, then we observer a small current flow

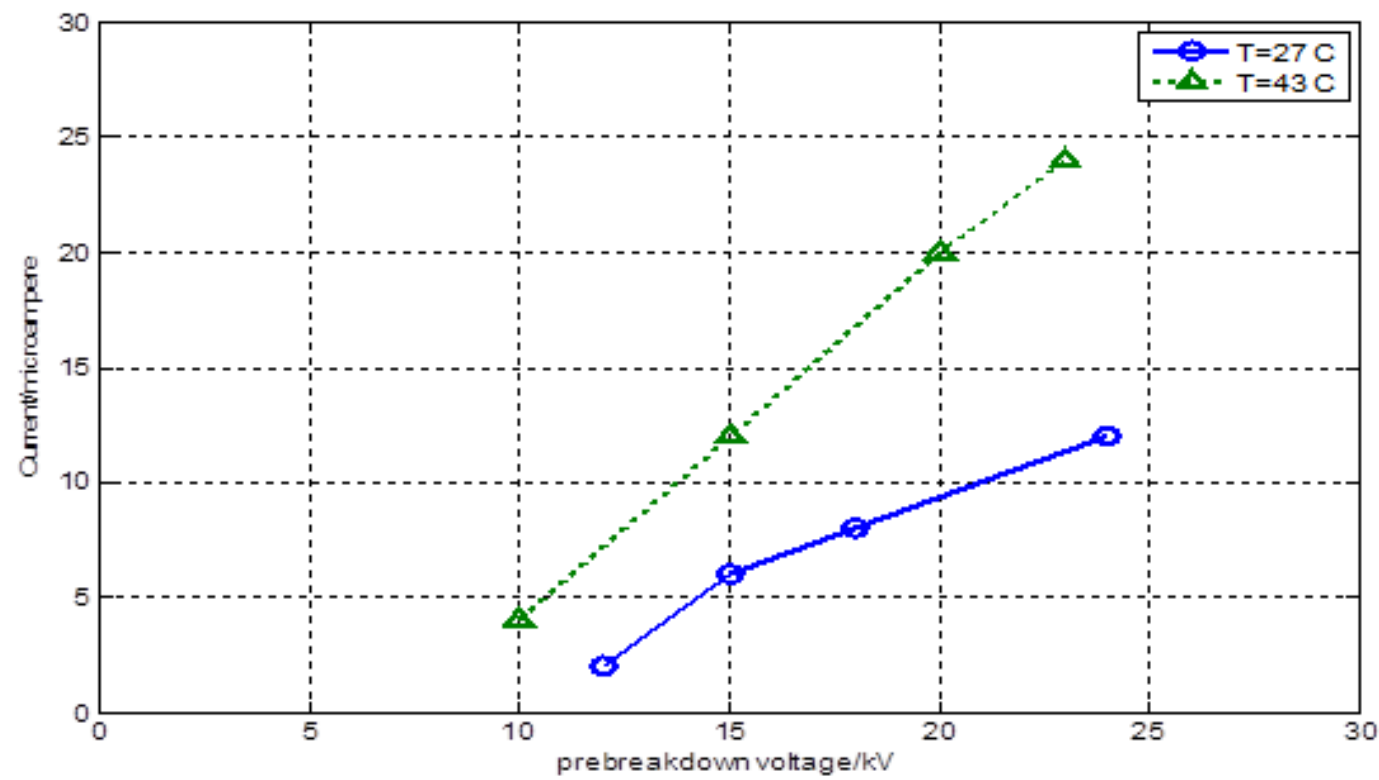

Fig.(8):Indicate the relationship between leakage current and pre-breakdown voltage for oil transformer with temperature $\left(27,43^{\circ} \mathrm{C}\right)$.

on CRO, as shown in figures .Also when increase the gauge of H.V. power supply, we seen that the current flow through pass the oil transformer can be large that meant very sharply (i.e enough voltage to breakdown occur ) 


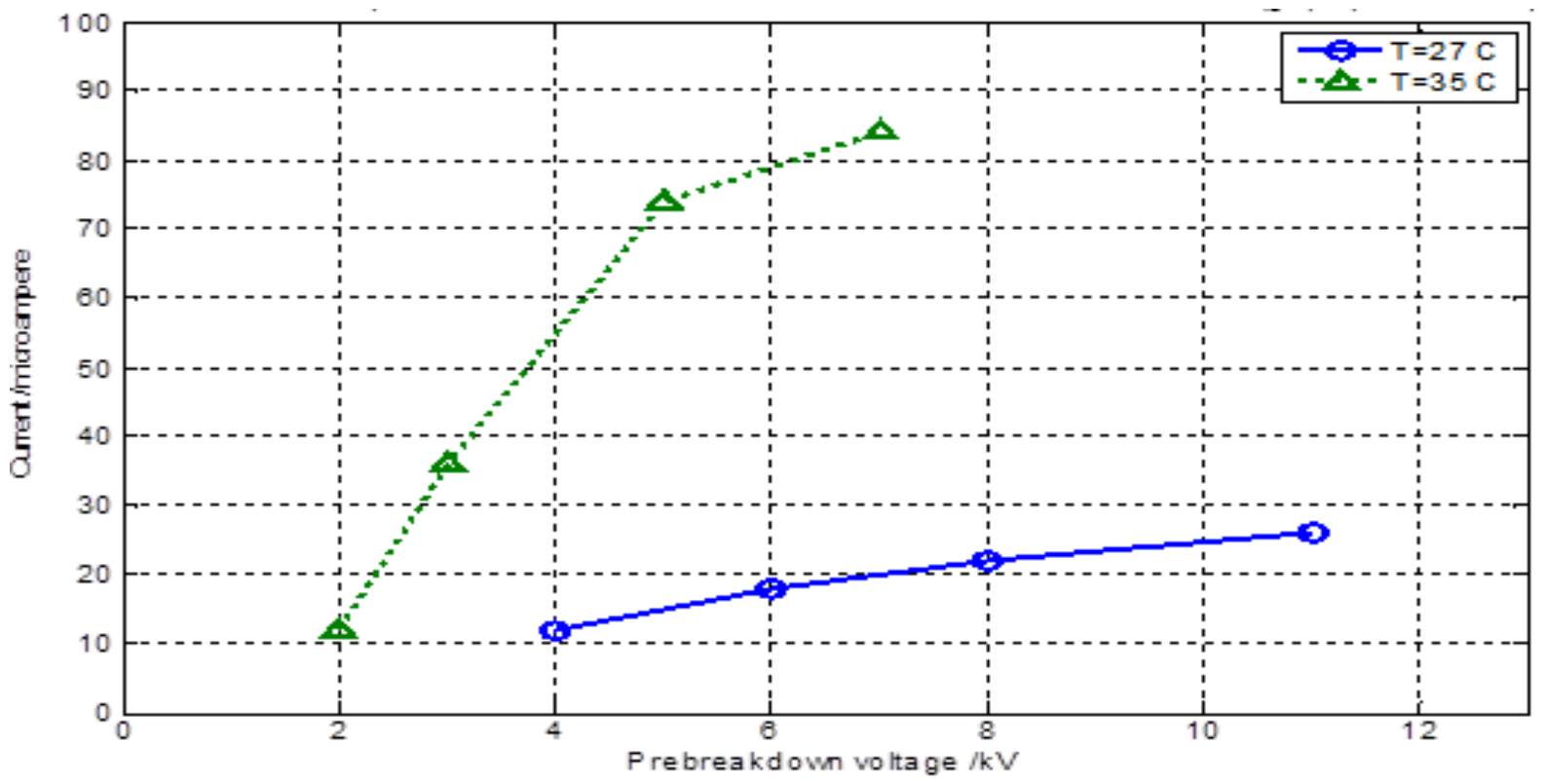

Fig.(9):Indicate the relationship between leakage current and pre-breakdown voltage for oil transformer with

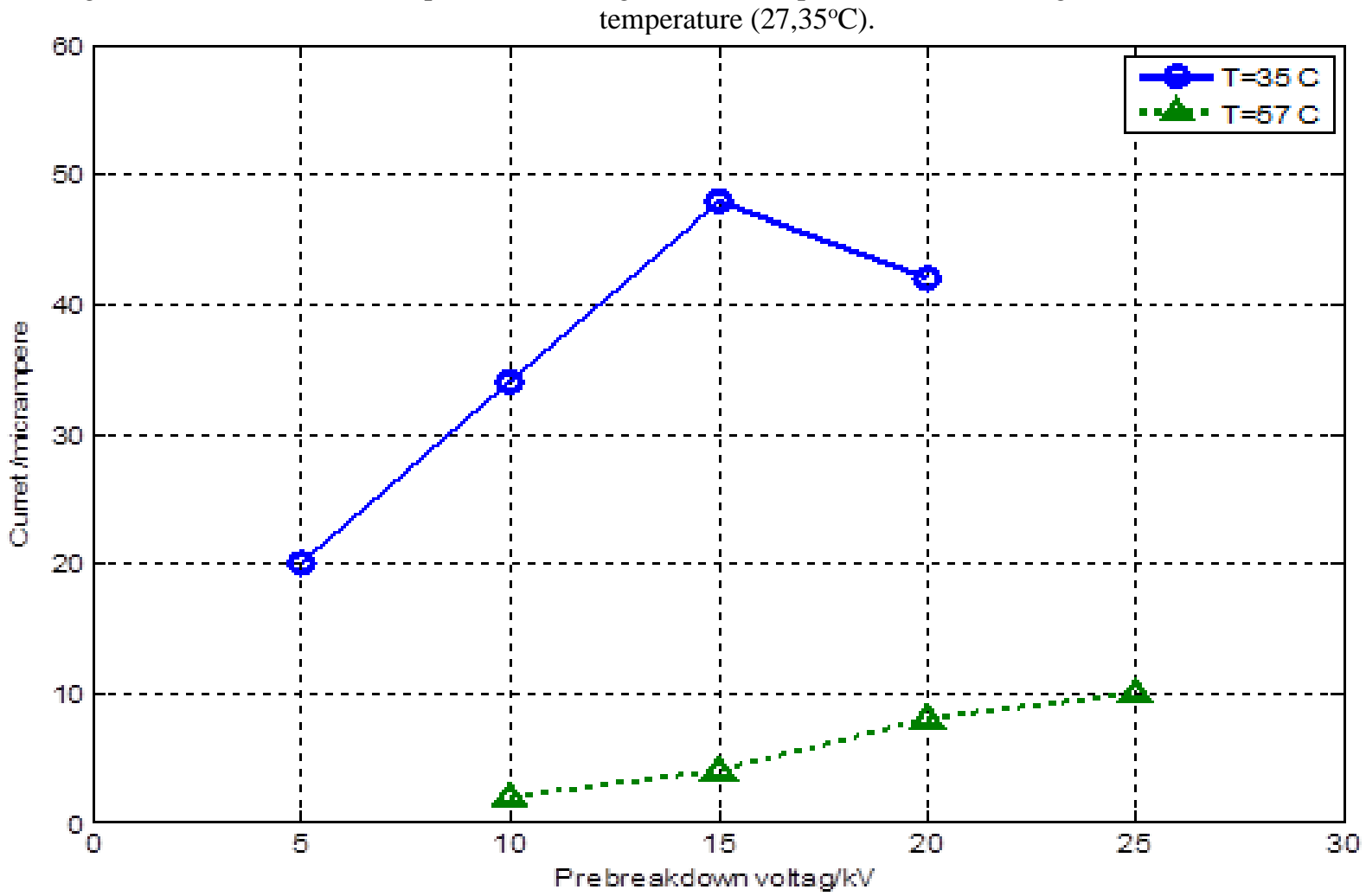

Fig.(10):Indicate the relationship between leakage current and pre-breakdown voltage for oil transformer with temperature $\left(35,57^{\circ} \mathrm{C}\right)$.

\section{Conclusion}

Many researchers have demonstrated the varies the discharge mechanisms in uniformity and non-uniformity fields. This enabled researchers to investigate detailed breakdown Processes in insulating liquids. The measurements are carrying out in divergent field produced by hemi- sphere to hemi-sphere electrodes configuration .

The present experimental setup was capable of producing bubble pre-breakdown and breakdown voltage in three variation temperatures by DC positive applied voltage $(0-70 \mathrm{kV}),(20 \mathrm{mAmp})$, over the range of gap length from (1 to $5 \mathrm{~cm}$ ), under humidity and Lab. ambient, 
We observer practically that in non- uniformity fields in oil transformer, pre-breakdown or initial voltage less than or smaller than the breakdown .

The measurements indicated the pre-breakdown and breakdown voltage increase if an increases the distance of gap, also decreases with increases the temperatures ,while the leakage current increases with increase the temperatures and gap spacing then decreases .

\section{References}

[1]. S. Austen Stigant ,A. C. Franklin" A Practical technology Of The Power Transformer " 1973.

[2]. Loeb L. B., Electrical coronas, their basic physical mechanisms, Univ.Calif. Press, Berkeley1965.

[3]. "Gaseous Dielectrics," Proceedings of the International Symposium on Gaseous Dielectrics, Knoxville, Tennessee, USA, March 6-8,1978.

[4]. Erich E. Kunhardt, Lawrence H. Luessen, "Electrical Breakdown and Discharges in Gases" Texas Tech University Lubbock, ,1981 .

[5]. E. Kuffel, W.S. Zaengl, J. Kuffel "High Voltage Engineering Fundamentals'" E. Kuffel, W.S. Zaengl and J. Kuffel. 2000

[6]. Philip K. Panicke," Ionization of Air by Corona Discharge " ,thesis ,University of Texas at Arlington in Partial Fulfillment. 2003.

[7]. A. Pedersen, "On the Electrical Breakdown of Gaseous Dielectrics" IEEE Transactions on Electrical Insulation Vol. 24 No. 5, 1988.

[8]. Yicheng Wang, "New Method for Measuring Statistical Distributions of Partial Discharge Pulses" Vol.102,No.5. 1997.
[9]. Essam Nasser, "Fundamental of Gaseous Ionization and plasma Electronics"(John Wiley,1971.

[10]. E. Marode, "The mechanism of spark breakdown in air at atmospheric pressure between a positive point and aplane.I.Experimental :Nature of the streamer track". Journal of Applied physics, Vol.46, No. 5, 1975.

[11]. M. S. Naidu, V. Kamaraju, "High Voltage Engineering Fundamentals'" , third edition tataMcGraw - Hill 2004.

[12]. Sari J. Laihonen ,"Polypropylene: Morphology, Defects and Electrical Breakdown" Universities service, US-AB, Stockholm, 2005.

[13]. A thesis submitted to The University of Manchester for the degree of PhD in the Faculty of Engineering and Physical Sciences "Partial Discharge Behavior's and Breakdown Mechanisms of Ester Transformer Liquids under AC Stress "School of Electrical and Electronic Engineering 2011.

[14]. Stefanos I. Spartalis, Michael G. Danikas, Georgia P. Andreou , George Vekris" Statistical Study of the Oil Dielectric Strength in Power Distribution Transformers" Journal of Electrical Engineering, Vol. 59, No. 2, 2008 pag. 68-74

[15]. Jozef Kudelcik, Miroslav Gutten, Pavel Virdzek "Measurement of electrical parameters of breakdown in transformer oil" Przeglad Elektrotechiczny (Electrical Review), Issn 00332097, R. 87NR8/2011. 